\title{
REQUALIFICAÇÃO DA ESTAÇÃO FERROVIÁRIA DE SANTO ANASTÁCIO-SP E SEU ESPAÇO FÉRREO.
}

\author{
Gabriele Rós da Costa. \\ Universidade do Oeste Paulista - UNOESTE, Faculdade de Engenharias e Arquitetura e Urbanismo \\ "Conselheiro Algacyr Munhoz Maeder", Presidente Prudente, SP. E-mail: \\ gabirobarc@hotmail.com.
}

\begin{abstract}
RESUMO
A cidade de Santo Anastácio está localizada no interior do estado de São Paulo, na região do Oeste Paulista. A mesma desenvolveu-se em virtude da implantação da linha férrea e das infinitas possibilidades que a Estação Ferroviária proporcionou há décadas atrás. O objetivo desta pesquisa foi buscar a valorização da memória do município, trazendo uma nova visão do antigo, além de entender que o patrimônio é essencial não só para manter a história em vida e as memórias em estado físico, mas para construir um futuro que queira entender suas identidades e respeita-las. A metodologia constou de levantamentos em campo, pesquisas bibliográficas e análises documentais. Os resultados foram alcançados e estudados para uma futura intervenção em preexistência. Concluí que a memória de um povo é seu maior bem e que este estudo visa o reconhecimento da identidade da cidade de Santo Anastácio.

Palavras-chave: Estação Ferroviária, Sorocabana, Patrimônio férreo, Santo Anastácio, Memória.
\end{abstract}

MEMORY STATION: RAILAY OF THE SANTO ANASTÁCIO-SP AND HIS STEELY SPACE.

\begin{abstract}
The city of Santo Anastacio is located in São Paulo, in the West Paulista region. The same was developed because of the railway line deployment and the infinite possibilities that the train station provided decades ago. The objective of this research was to seek recovery of the city's memory, bringing a new vision of the old, and understand that heritage is essential not only to keep the story alive and the memories in physical state, but to build a future you want understand their identities and respects them. The methodology consisted of field surveys, literature searches and desk reviews. The results were obtained and studied for a future intervention in preexistence. I concluded that the memory of a people is its greatest asset and that this study aims to recognize the identity of the city of Santo Anastácio.
\end{abstract}

Keywords: Railway Station, Sorocabana, Steely Heritage, Santo Anastácio, Memory. 


\section{INTRODUÇÃO}

Atualmente, com a facilidade de outros meios de locomoção de mercadorias e pessoas, os trens foram dispensados, fazendo com que a área que antes fora o ápice do crescimento das cidades, acabasse em desuso e abandono, além de manter o espaço ocioso e nocivo para os moradores. Não diferente na cidade de Santo Anastácio com pouco mais de 20.000 habitantes. A estação ferroviária está inserida no centro da cidade e é conceituada como o embrião do tecido urbano, todavia, sem conservação devido à falta de uso e manutenções.

De acordo com Rufino (2006), a recuperação do patrimônio ferroviário propicia um cenário de mudanças no ambiente, ocasionalmente estas áreas se transformam em obsoletas devido aos processos de não utilização da linha férrea e a reestruturação econômica do cenário atual. A transformação desses e espaços aderindo valor e uso requalifica todo o entorno e enaltece a memória social construída pelo tempo

\section{METODOLOGIA}

O presente estudo foi desenvolvido a partir de levantamentos bibliográficos através de leituras e pesquisas embasadas em livros, artigos e materiais disponibilizados na internet. Foi desenvolvido também através de levantamentos documentais no Acervo Histórico da cidade e na Prefeitura Municipal da mesma. Houve levantamentos em campo, métricos e fotográficos para melhor compreensão do espaço.

\section{RESULTADOS}

Os resultados obtidos foram optar pela requalificação do espaço. Os edifícios e equipamentos possibilitam ao individuo e à comunidade, a valorização de sua história até para a população que não participaram do momento em que estes lugares estavam sendo produzidos. Através de reabilitação do espaço urbano degradado, esses espaços podem ser recuperados, formalmente ou construtivamente, visando à revitalização da paisagem, inserindo o conjunto no cotidiano da cidade para novos usos e um novo paradigma de desenvolvimento. (MONASTIRSKY, 2006).

\section{DISCUSSÃO}

Santo Anastácio está localizado no interior de São Paulo, na região do Oeste Paulista, próximo a Presidente Prudente e possui mais de 20.000 habitantes. (IBGE, 2010).

A cidade começou a ser povoada em 1917 e obteve seu crescimento após o ano de 1920, com a inserção da Estrada de Ferro Sorocabana, na região da Alta Sorocabana. O povoado antes denominado de "Vai e Vem", passou então a ser Vila e distrito de Presidente Prudente em 1921. Em 1925 a Vila se emancipa e passa a chamar-se cidade de Santo Anastácio. (JUNIOR, 1995).

A estrada de Ferro Sorocabana foi por muito tempo o principal meio de transporte de passageiros e de cargas. A extensão da cidade até a capital era de cerca de $760 \mathrm{~km}$ pela ferrovia. Servia ao município numa distancia de $14 \mathrm{~km}$ e uma estação ferroviária com dois pontos de parada. (JUNIOR, 1995).

Nos anos 60, a estação recebia constantemente os mais diversos pontos do Estado, aproximadamente nove trens, estes transportavam desde passageiros, produtos agrícolas até gado. Na época, a primeira composição de passageiros chamava-se de Ouro Verde, este nome se referia ao café e a legenda sempre vinha estampada nos vagões. Posteriormente, surgiu a legenda chamada Ouro Branco, referia-se ao algodão. (JUNIOR, 1995).

Santo Anastácio foi à última estação a cancelar o embarque e desembarque de passageiros no trecho entre Prudente Epitácio, já estando inativa quando os trens foram suprimidos em 1999. (GIESBRECHT, 2014). 
Através da privatização da Companhia Ferroviária Paulista S.A para FEPASA, os prédios antigos antes usados para embarque e desembarque de cargas transfiguraram-se a prédios abandonados. (PISTORI, 2008). O mesmo acontece com a estação de Santo Anastácio, dos dois prédios que foram inseridos na época, apenas um está em uso atualmente: o galpão para serviços de serralheria.

A estação Ferroviária é composta por duas edificações, a antiga sede da Estação, que se transformou em Biblioteca Municipal, Escola de escoteiros, posteriormente Museu Municipal e atualmente está fechada por patologias de risco em sua forração. Ao lado da sede da estação está inserido o antigo armazém (galpão), que hoje exerce função de oficina de Serralheria.

A solução mais coerente para resolver o problema do abandono e descaso com a memória e patrimônio da Estação Municipal, seria promover uma atividade turística e cultural, logo, a estação e seus arredores não estagnariam, e iriam servir como ponto atrativo para a cidade.

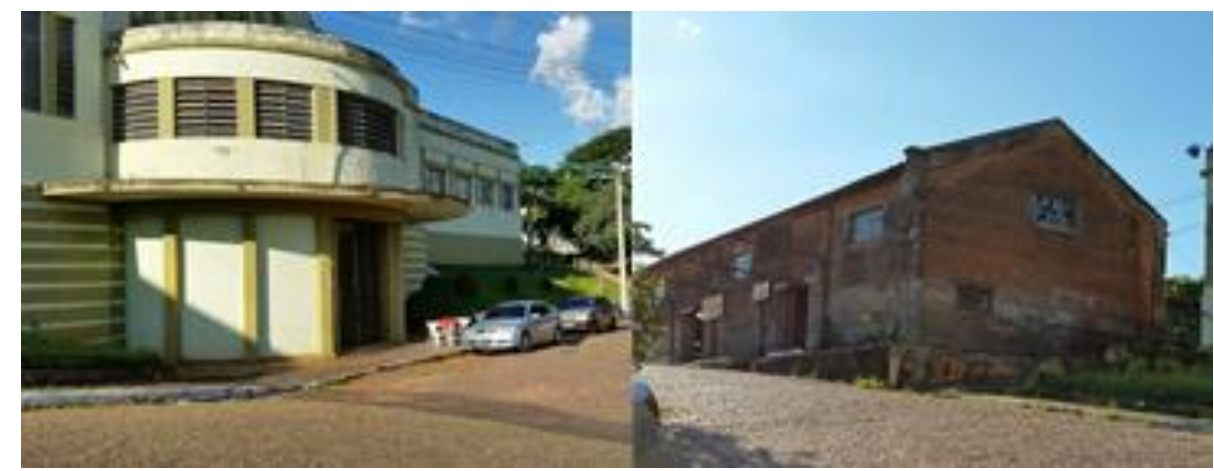

Figura 03. Imagens do prédio da estação e do galpão, respectivamente.

Fonte: Autora, (2016).

De acordo com Allis (2006):

[...] o patrimônio cultural ferroviário, é composto por toda a gama de construções e materiais remanescentes de outras épocas da ferrovia, que, com ou sem uso atualmente, despertam interesse de manutenção nos ambientes em que se materializam e prometem alguma exploração turística. (p. 124).

Para dar novamente "alma" a estação ferroviária de Santo Anastácio, seria necessária uma transformação no espaço que é considerado patrimônio cultural ferroviário. No que é referente a patrimônio ferroviário, é viável a ideia de que pela decadência desse tipo de transporte, os espaços sofram deterioração, então, estas áreas possuem uma visibilidade negativa e com grandes espaços vazios. (POZZER, 2006).
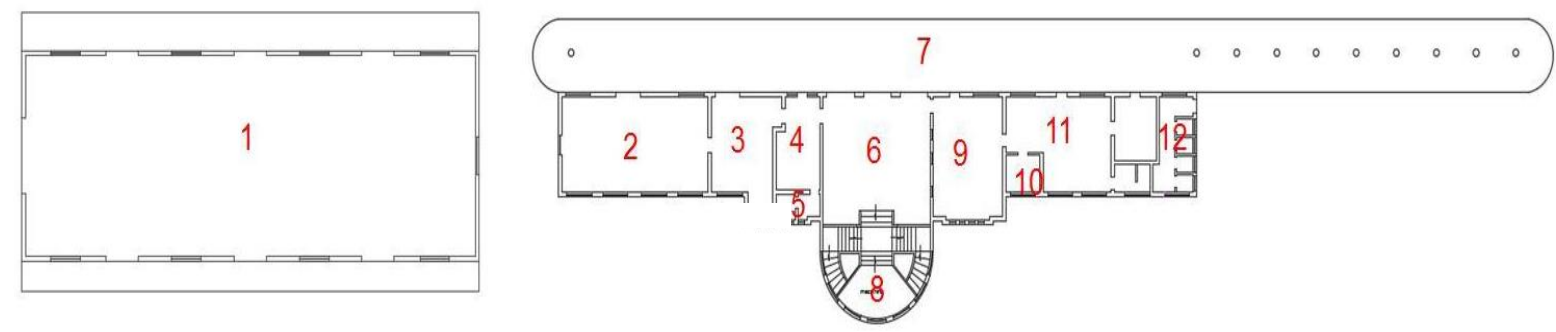

Figura 04. Planta baixa do galpão e do prédio da estação. (Sem escala). Fonte: Prefeitura Municipal de Santo Anastácio, (2013), editado pela Autora, (2016). 
Legenda: 1 - Galpão (Armazenagem e manutenção de maquinários), 2 - Depósito, 3 Cozinha, 4 - Sala de Espera, 5 - Banheiros, 6 - Saguão, 7 - Plataforma, 8 - Mezanino, 9 Bilheteria, 10 - Arquivo, 11 - Administrativo, 12 - Banheiros.

O volume retangular - galpão - (fig. 4) possui diversas aberturas, como janelas e portas de ferro e atualmente funciona apenas como oficina de serralheria, há décadas atrás serviu como local de armazenamento e manutenção de maquinários. Tem seu involucro feito de alvenaria e tijolo aparente. A cobertura principal é constituída por meio de duas águas sustentadas por treliças metálicas.

As características arquitetônicas predominantes da Estação Ferroviária são notáveis pela sua forma preservada, sua planta baixa (fig. 4) é basicamente um retângulo e não há presença de corredores, sendo assim, as salas são interligadas umas com as outras. Todas as áreas internas possuem uma porta que dá saída para o pátio. Ainda é composta por um volume cilíndrico no centro de sua fachada, principal entrada para o edifício.

Em seu interior, há duas escadarias curvilíneas que levam o público ao saguão. São oito salas não incluindo os banheiros. Saindo do saguão até o pátio de concreto há 10 pilares cilíndricos de porte grande, estes dão sustento à cobertura plana. O prédio já serviu como biblioteca, escola de escoteiro e museu, atualmente está desativado em espera de manutenções. O pátio e toda a obra foram construídos de concreto, portas e janelas de ferro e piso granilite.

Dentro do saguão ao lado direito, encontra-se a bilheteria com duas portas e uma saída que leva até a plataforma de embarque, a outra saída leva até o saguão, o prédio possui duas salas administrativas, sala de arquivo e sanitário. Ao lado esquerdo do saguão, havia uma sala de espera com duas portas, sanitários, cozinha e depósito.

Por volta do século XIX, a arquitetura passa por um período de crises devido a falta de referenciais, só no fim do século XIX propaga-se a pureza formal e surge a divulgação do Art Nouveau, consolidando seu caráter formal da arquitetura ferroviária. Nas próximas décadas, no século XX, o ecletismo estava no auge como representação arquitetônica. (KUHL, 1998).

A estação possui estilo arquitetônico Art Déco. Estilo muito utilizado nas estações ferroviárias da época, e não somente nas estações como também em vários prédios púbicos do país. Esse estilo decorativo internacional surgiu na França e atingiu seu auge no período da Primeira Guerra Mundial. O nome Art Déco obteve origem na Exposição Internacional de Artes Decorativas e Industriais Modernas, em Paris no ano de 1925. (DEMPSEY, 2003).

As principais características utilizadas no edifício são suas formas regulares e aerodinâmicas, o volume frontal consiste num cilindro a frente de um quadrado que se encontra interligado ao retângulo. Em sua fachada há reentrâncias e volumes destacados, principalmente os do acesso, ao percorrer de toda a fachada, estão dispostas janelas de forma simétrica. O relógio era sinônimo de prestígio na época, nota-se a presença deste no topo da fachada da estação.

É possível notar as patologias desde o hall de entrada, o revestimento de ganilite da escada está lascado em diversos degraus. A forração do mezanino se soltou devido a intempéries e a antiga sala de bilheteria não possui cobertura. As telhas e sua estrutura estão aparentes, já que a cobertura foi retirada para evitar acidentes, já estando em ruína.

As paredes e lajes do saguão estão repletas de rachaduras e mofos, além do descascamento da pintura. A bilheteria, administração e o depósito que possuem piso de taco, estão faltando algumas peças e mostrando o contrapiso. Os ladrilhos que revestem alguns ambientes estão quebrados, caíram ou estão amarelados. No banheiro da sala de espera, faltam alguns pisos de azulejo, e também estão com o contrapiso aparente. As janelas da bilheteria e da parte posterior estão quebradas. 
Uma parte da laje da sala de espera está com ferragem e concreto aparente. A cobertura da plataforma está com excesso de infiltrações, o vidro das janelas estão danificados e as paredes externas estão pichadas. O galpão ao lado da estação está com as paredes chamuscadas e pintadas, porém algumas janelas estão com vidros quebrados.

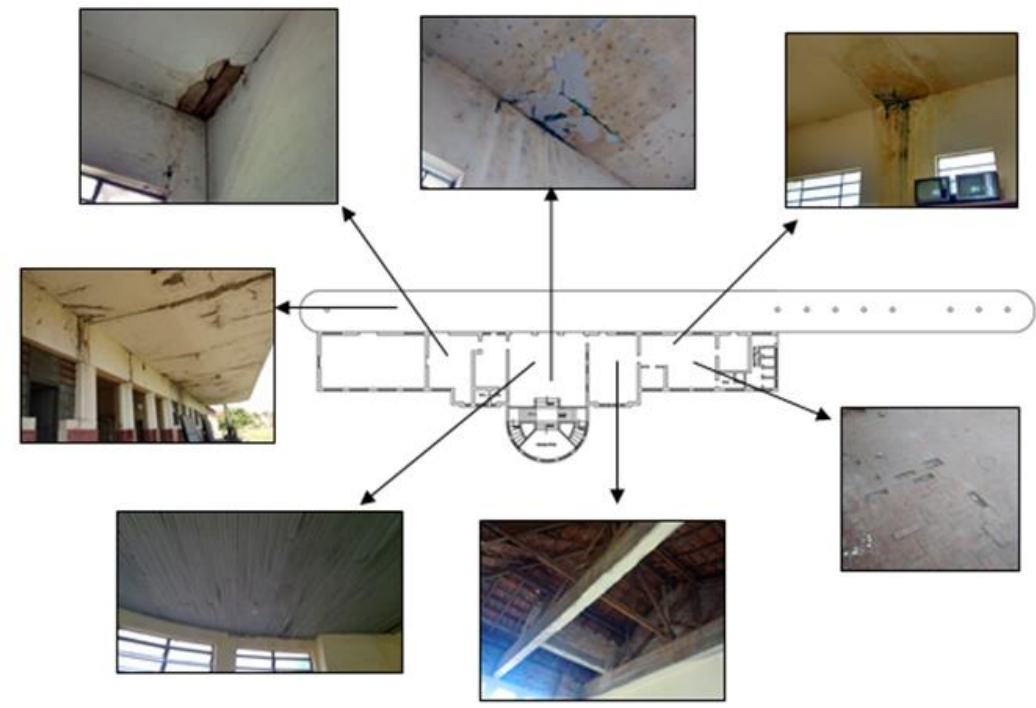

Figura 05. Fotografias das patologias no prédio da estação.

Fonte: editado pela Autora, (2016).

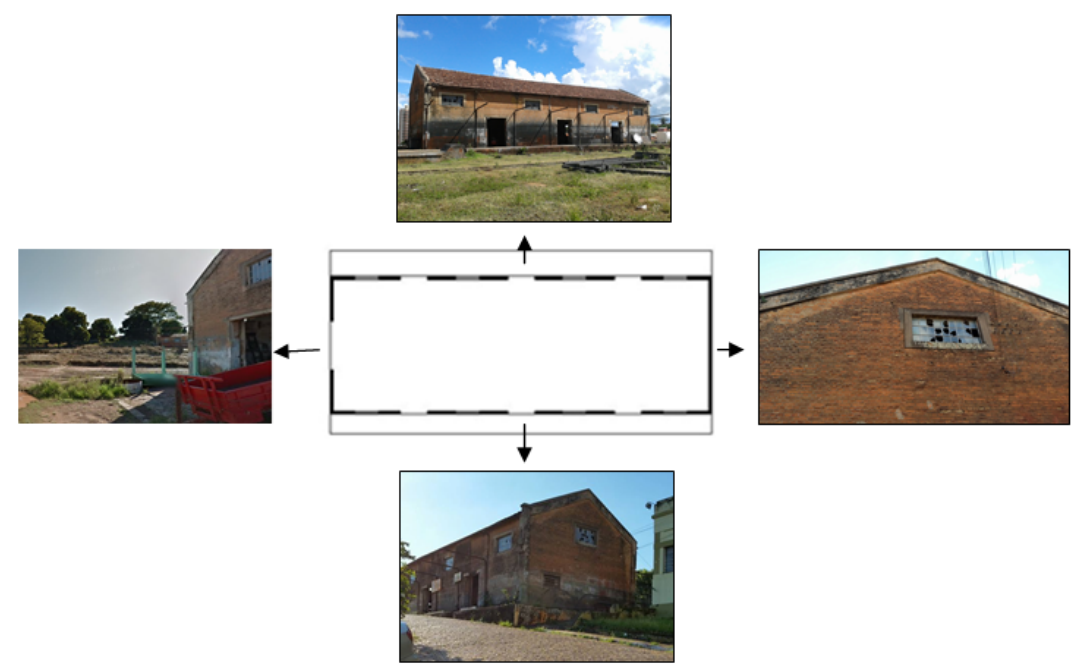

Figura 06. Fotografias das patologias do galpão.

Fonte: editado pela Autora, (2016).

\section{CONCLUSÃO}

A estação Ferroviária de Santo Anastácio necessita de um auxílio cultural para que suas preexistências adquiram um novo uso e novos olhos, porém sem retirar sua essência como patrimônio. Ou seja, uma requalificação de suas edificações e de seu espaço férreo fará com que o espaço seja valorizado. As preexistências deverão ser restauradas e frequentadas, logo, mantendo viva a memória do município. 


\section{REFERÊNCIAS}

ALLIS, T. Turismo, patrimônio cultural e transporte ferroviário. Um estudo sobre ferrovias turísticas no Brasil e na Argentina. 2006232 f. Dissertação (Pós-graduação em Integração da América Latina) - Universidade de São Paulo, São Paulo, 2006.

DEMPSEY, A. Estilos, Escolas e Movimentos. 1 ed. São Paulo: Cosac Naify, 2003.

GIESBRECHT, R. M. Estações Ferroviárias do Brasil. Disponível em: < http://www.estacoesferroviarias.com.br/s/stoanastacio.htm />. Acesso em: 13 abr. 2016.

IBGE. Santo Anastácio. Disponível em: <http://cidades.ibge.gov.br/painel/painel.php?codmun=354770> . Acesso em: 01 abr. 2016.

JUNIOR, C. J. A. Santo Anastácio: História de uma Cidade. 1 ed. Porto Alegre: Evangraf, 1995.

KUHL, B. M. Arquitetura do ferro e arquitetura ferroviária em São Paulo: reflexões sobre a sua preservação. São Paulo: Ateliê Editorial, 1998.

MONASTIRSKY, L. B. Ferrovia: Patrimônio Cultural, Estudo sobre a ferrovia brasileira a partir da região do Campos Gerais (PR). 2006. 190 f. Tese (Pós-Graduação). Universidade Federal de Santa Catarina, Santa Catarina, 2006.

PISTORI, T. T. Memória do Café: A estação ferroviária de Descalvado. 2008. 61 f. Monografia (Curso de Turismo) - Universidade Estadual Paulista, Rosana, 2008.

POZZER, G. P. Arqueologia e Patrimônio Industrial: A Estação Cultura em Campinas. In: XVIII ENCONTRO REGIONAL DE HISTÓRIA DA ANPUH/UNESP, 2006, Assis. Anais eletrônicos... Assis: ANPUH/UNESP, $2006 . \quad$ Disponível em: http://www.anpuhsp.org.br/sp/downloads/CD\%20XVIII/pdf/ST\%2027/Guilherme\%20Pinheiro\%20 Pozzer.pdf. Acesso em: 16 abr. 2016.

RUFINO, S. Os dois lados da linha do trem: história urbana e intervenções contemporâneas em Campinas (SP). In: FRÚGOLI J. H.; ANDRADE, L, T.; PEIXOTO, F. A. (Org.). As cidades e seus agentes: práticas e representações. Belo Horizonte: PUC Minas/Edusp, 2006. p. 68-97. 